\title{
ist \\ O progresso do homem brasileiro pelo mecanismo de seleção natural em Miranda Azevedo
}

Ricardo WAIZBORT

\begin{abstract}
孟
RESUMO

O objetivo deste trabalho é apresentar como a palestra de Miranda Azevedo, "Darwinismo: seu passado, seu presente, seu futuro", proferida nas Conferências Populares da Freguesia da Glória, em 1875, articula os conceitos de evolução, evolução humana, progresso e a ideia do homem como ápice da evolução e controlador das leis seletivas que regulam a natureza. Para tanto apresentaremos e analisaremos o texto publicado em 1876 que contém na íntegra o discurso de Azevedo. De particular importância é a filiação de Azevedo a Haeckel, já anteriormente indicada pela historiografia brasileira. Ao contrário dos estudos dedicados ao tema, pretendemos mergulhar mais detidamente no texto de Azevedo com o objetivo de mostrar como ele relaciona a hereditariedade e os processos pretensamente seletivos para a partir daí pensar em como fazer as novas gerações brasileiras progredirem.
\end{abstract}

Palavras-chave • Brasil. Darwinismo. Evolução. Seleção natural. Progresso. Hereditariedade.

\section{INTRODUÇÃO}

No dia 16 de dezembro de 1874 , Miranda Azevedo defendia, perante a banca examinadora da Faculdade de Medicina do Rio de Janeiro, sua tese de doutorado intitulada Beribéri. O texto apresentado para a defesa da tese era constituído de uma dissertação sobre o beribéri (que fazia parte da "seção médica - cadeira de patologia interna") e de proposições acessórias, que representavam a estrutura interna do curso de medicina da época (cf. Azevedo, 1875; Collichio, 1988; Cid, 2004). A tese Beribéri, de um modo geral, é uma longa revisão bibliográfica da literatura, disponível na época, sobre essa doença. Como muitos outros médicos do mesmo período, Miranda Azevedo atribui à ação de um microrganismo a causa de um mal que, sabemos hoje, está relacionado à deficiência de vitamina B1. A dissertação foi aprovada com louvor (cf. Cid, 2004).

As seções acessórias ao corpo principal da tese eram: (1) "secção acessória - cadeira de botânica e zoologia”; (2) "secção cirúrgica - cadeira de medicina operatória”; 
(3) "secção médica - cadeira de higiene". As proposições eram respostas em tópicos, sobre perguntas formuladas pelos professores da Faculdade de Medicina. Relativa à "secção acessória - cadeira de botânica e zoologia', o botânico Joaquim Monteiro de Caminhoá fez a seguinte pergunta a Azevedo: "do darwinismo - é aceitável o aperfeiçoamento cada vez mais completo das espécies até o homem?” (Azevedo, 1875).

Chamo a atenção do leitor, desde o início, que na própria pergunta de Caminhoá está embutida a ideia de uma escala, que vai do menos ao mais aperfeiçoado, e que isso indica fortemente que o professor, com sua interrogação, punha em cena o pensamento de que as espécies de seres vivos poderiam ser organizadas em uma cadeia ascendente de complexidade, a scala naturae, com o homem no ápice dessa estrutura (cf. Bowler, 1989).

Desde a primeira das dezoito proposições, Miranda Azevedo define o darwinismo como a teoria genealógica que sustenta a derivação de todos os organismos existentes, extintos e futuros, vegetais e animais, a partir de um pequeno número de tipos antepassados, excessivamente simples e transformados por uma evolução ou metamorfose gradativa. Ele opõe o darwinismo à teoria mosaica ou teleológica, excluindo a hipótese de uma criação simultânea de todas as espécies. Citando supostos precursores da teoria da evolução, afirma que a variabilidade animal e vegetal é uma das bases do darwinismo, doutrina que reinterpreta os resultados de brilhantes naturalistas antievolucionistas, principalmente Lineu e Cuvier. Azevedo também se refere à geologia de Lyell como uma base sólida para o gradualismo do processo da evolução, reconhecendo o tempo profundo como uma condição para a mudança das espécies. Também faz referência ao mecanismo da herança de características adquiridas e da seleção natural; enumera quatro leis gerais que formariam o núcleo do darwinismo; posiciona-se contra as objeções à teoria; resume os "grandes raios de luz na questão do darwinismo": a anatomia e a fisiologia comparadas, a ontogenia e a teratologia (cf. Azevedo, 1875). Ao fim de quatro páginas, na proposição xvi, Miranda Azevedo responde de forma explícita à pergunta de Caminhoá sobre a evolução humana:

Destruídas as barreiras artificiais entre as espécies, reconhecida a sua variabilidade, cruzamento, a transformação gradual dos indivíduos, e seu aperfeiçoamento em escala ascendente pela seleção e hereditariedade, demonstrada a analogia do homem com os animais e a sua existência pré-histórica, pelas descobertas nestes últimos tempos, verificadas em diversas zonas geológicas, o darwinismo tornouse uma doutrina sistemática cujas últimas consequências a lógica exige imperiosamente: o aperfeiçoamento, pois, cada vez mais completo das espécies até o homem é uma verdade posta em evidência pelo Darwinismo! (Azevedo, 1875, s.p.). ${ }^{1}$ 
Tais proposições são consideradas pela historiografia das ciências como as primeiras referências positivas à teoria de Darwin no Brasil (cf. Collichio, 1988; Domingues et al., 2003). Positiva no sentido de serem palavras que expunham a teoria de modo a propagar suas supostas verdades, não para contestá-las ou depreciá-las. Embora tenham valor como primeiras manifestações do darwinismo em nossas terras, no entanto, por serem tópicas, não permitem uma visão mais geral sobre o modo como Miranda Azevedo concebe e articula o processo da evolução e o lugar da espécie humana nesse processo.

Tal desenvolvimento ocorreria de forma mais evidente em 1875, nos concorridos eventos então conhecidos como as Conferências Populares da Freguesia da Glória (cf. Azevedo, 1876). Realizadas e promovidas por Francisco Manuel Correia, as conferências tornaram-se uma espécie de ponto de encontro da elite fluminense entre ${ }_{1873}$ e 1880, destinada à apresentação de temas considerados importantes para o progresso científico e social do Brasil (cf. Fonseca, 1996). Miranda Azevedo proferiu seis conferências sobre o darwinismo. Apenas a primeira, um ano mais tarde, em 1876, foi publicada sob a forma de texto (cf. Fonseca, 1996; Cid, 2004), e será nosso objeto principal neste trabalho.

Esse primeiro uso do darwinismo no Brasil é aproximadamente contemporâneo às primeiras recepções dessa teoria em alguns países ibero-americanos, como Argentina, Uruguai e Cuba. O que é mais peculiar no caso brasileiro é que, assim como no México, as primeiras discussões sobre a evolução foram centradas na espécie humana (cf. Glick et al., 1999). No caso de Miranda Azevedo, como veremos, trata-se de usar o darwinismo como ferramenta conceitual para vislumbrar o melhoramento do homem brasileiro.

Os estudos das primeiras recepções do darwinismo, na Europa e nas Américas, são muito volumosos, e não há espaço no presente trabalho para dar sequer um panorama do que estava ocorrendo nos países desses continentes quando Azevedo teve seu texto publicado. Para uma introdução, remeto o leitor, então, aos trabalhos mais específicos sobre o tema, ressaltando um dos marcos do estudo sobre a recepção do darwinismo no mundo, The darwinian heritage, editado por Thomas Khon, em 1982. Nessa obra, além de artigos mais teóricos e filosóficos sobre a estrutura do pensamento de Darwin e suas relações com a sociedade vitoriana, há trabalhos sobre a recepção na Inglaterra, Estados Unidos, França, Alemanha, Itália e Rússia. Nesse livro, encontra-se o artigo seminal do filósofo da biologia David Hull, "Darwinism as a historical entity", no qual ele se pergunta por uma definição de darwinismo, ${ }^{2}$ concluindo que, assim como as

2 A questão sobre o que é o darwinismo é uma das mais polêmicas da história da biologia. Embora no presente trabalho adotemos a definição do darwinismo como uma teoria ou sistema conceitual comprometido com o meca- 
espécies biológicas, o darwinismo é uma entidade histórica que não possui uma essência, mas é um sistema conceitual que mantém uma certa identidade enquanto muda com o tempo (Hull, 1982). Ainda no livro editado por Khon, o conhecido historiador do darwinismo, Peter Bowler, no artigo "Scientific attitudes to darwinism in Britain and America" ressalta o pioneirismo do historiador americano Thomas Glick, que em 1974 organizou a coletânea de artigos intitulada The comparative reception of darwinism, que contém artigos sobre a recepção do darwinismo na Inglaterra, Estados Unidos, França, Rússia, Espanha, México, Holanda, e também um artigo sobre o impacto do darwinismo no mundo islâmico (cf. Bowler, 1982; Glick, 1988). Desde 1972, Thomas Glick, ao lado do espanhol Miguel Ángel Puig-Samper, da mexicana Rosaura Ruiz e outros promoveram congressos que redundaram em livros contendo trabalhos sobre a recepção do darwinismo na Espanha, no México, na Argentina, em Cuba, no Brasil, no Uruguai, no Chile, entre outros países (cf. Glick, 1988; Glick et al. 1999).

Ao que tudo indica, todos os trabalhos de recepção do darwinismo na IberoAmérica tratam de autores que estão claramente comprometidos com a ideia de progresso, ideia fortemente tributária da concepção de darwinismo social atribuída a Herbert Spencer. Para Spencer, a evolução é sempre progressiva, um processo de diferenciação ao longo do tempo que leva inexoravelmente a melhorias e ao aperfeiçoamento do que quer que seja material ou espiritual na Terra. Se Darwin foi um darwinista social ou não é um tema que não trataremos aqui. Certamente, ele via o progresso (local e historicamente mantido) como uma consequência do processo de adaptação, levando a estruturas e comportamentos melhores, mais adaptados, para uma determinada espécie, em uma geografia e em um tempo específicos. Isso valia, segundo ele, também para a espécie humana.

Também não há espaço aqui para apresentar e discutir a importância do darwinismo social, considerando apenas que no Brasil, como em outras partes do mundo, incluindo a França, a influência do evolucionismo de Ernst Haeckel foi muito intensa, sobretudo entre os médicos do Rio de Janeiro e da Bahia, segundo a historiografia brasileira. Nesse contexto uma influência mais marcante de Spencer teria acontecido sobre os juristas da Escola do Recife e de São Paulo (Domingues \& Sá, 2003; Gualtieri, 2008). O darwinismo a que vamos nos referir no decorrer deste trabalho é uma manifestação de um darwinismo social mais relacionado a Haeckel.

Durante o período em que viveu Azevedo, o Brasil passava por grandes transformações sociais, culturais e econômicas. Monarquia, escravidão, economia baseada em

nismo da seleção natural, sabemos que essa definição exclui adeptos e defensores históricos da teoria da evolução de Darwin. Todavia, na falta de um consenso sobre o tema, será preferível arriscar assumir uma definição não compartilhada por todos do que incorrer no risco de falar de uma entidade vaga. 
trabalho escravo, e diversas estruturas da sociedade imperial começavam a ser questionadas. Ao mesmo tempo emergia um novo movimento intelectual, que foi uma consequência da crise pela qual passava o Império. Tal fenômeno ocorreu pela incapacidade das instituições políticas em dar respostas aos anseios de grupos da própria comunidade política. Essa incapacidade gerou a crise que permitiu uma "expansão da "estrutura de oportunidades políticas"' (Alonso, 2002, p. 411). Para que essa ação tivesse efeito, os integrantes do movimento utilizaram-se das novas perspectivas intelectuais vindas da Europa como repertório de ação política. O repertório consistia em um conjunto de padrões analíticos, conceitos, teorias e formas estilísticas de linguagem. Seria uma espécie de "caixa de ferramentas" (Alonso, 2002, p. 176). A caixa de ferramentas era utilizada de forma seletiva por esse grupo de atores que, nesse período, passou a ser conhecido como "geração de 1870 ". Entre essas ferramentas estavam o evolucionismo e o darwinismo (cf. Cid, 2004).

Note-se que até agora nos furtamos de apresentar uma definição de darwinismo pela qual pudéssemos balizar sua recepção no Brasil. Para nós, darwinismo é uma das formas de evolucionismo (a teoria científica sobre as transformações das espécies de seres vivos ao longo do tempo na Terra). E, para nós, o darwinismo, sobretudo em sua forma epistemológica mais forte, implica um comprometimento com o processo da seleção natural compreendido como um processo semiestocástico e parcialmente diretivo. Na época de Darwin, poucos foram aqueles que alcançaram o significado estatístico do funcionamento da seleção natural, definida aqui em termos atuais: "em um dado ambiente $X$, os indivíduos $Y$ de uma população $P$, portadores da característica $C$, têm uma chance ou propensão maior de passar seus genes adiante". De qualquer forma, a nosso ver, a seleção natural não é apenas o fole do processo da evolução, mas um processo mais geral que inclui a seleção sexual e a seleção social. São processos seletivos que conferem uma aparência de projeto aos indivíduos biológicos do mundo (cf. Dennett, 1998).

No Brasil, a chamada geração de 187 o inicia o processo de valorização da ciência experimental, face a uma concepção de conhecimento mais essencialmente retórica e bacharelesca (cf. Sá, 2006). Diferente de outros homens de geografias distintas, sobretudo na Europa, e análogo ao que ocorreu em outros países ibero-americanos, Azevedo não era um cientista que elaborou por si mesmo pesquisas experimentais, mas mobilizou conhecimentos científicos mais ou menos abalizados, no sentido de servir de instrumento político na batalha contra uma forma de saber considerada ultrapassada, enciclopédica e verborrágica.

Nosso objetivo, no presente trabalho, é mostrar como o texto da conferência de Azevedo apresenta uma concepção particular do que seja o darwinismo, assim como especula sobre o lugar destinado à evolução da espécie humana. Não é nossa intenção 
mostrar que o uso que ele fez do darwinismo não é correto epistemologicamente, que não se encaixa nas formas com as quais cientistas europeus como Darwin, Wallace, Huxley, Spencer, Haeckel, entre muitos outros, concebiam o processo da evolução, incluindo a evolução humana. Como já assinalado, o entendimento que esses autores tiveram do evolucionismo não coincide (cf. Hull, 1982). Aliás, podem discordar muito, principalmente sobre a importância da seleção natural para explicar a diversidade e a adaptação evolutivas, incluindo mais uma vez a diversidade e as adaptações humanas. Trata-se de perguntar como Azevedo representa o processo da evolução em seu texto, mais especificamente, como ele concebeu a evolução da espécie humana como um processo natural. Veremos que, embora tenha de fato expressado uma compreensão superficial do mecanismo evolutivo proposto por Darwin, Azevedo contribuiu para romper o silêncio que durante mais de dezesseis anos espaçaram a publicação de $A$ origem das espécies (cf. Darwin, 1985 [1859]), e o ano que tomamos como base, 1875 e 1876 , tornando públicas ideias contidas no livro de Darwin, constituindo-se assim como uma fonte de informação que acabaria por alimentar vários ideais da elite brasileira, entre elas a República e o fim do regime escravocrata.

Diferente da maioria dos estudos sobre a recepção do darwinismo no Brasil e ao redor do mundo, nosso interesse aqui é mais estritamente literário, no sentido da nossa intenção metodológica, de mergulhar um pouco mais detidamente no texto do autor em questão para deduzir desse mergulho como ele concebeu a evolução em geral e a evolução humana em particular. Veremos como ele usou o darwinismo para indicar saídas para impasses de um país em formação, argumentando que o futuro civilizado do Brasil dependia do reconhecimento e da aceitação de que o progresso humano era uma consequência inevitável de descobertas científicas que estavam mudando a face do planeta e a compreensão de sua história natural.

Collichio é verdadeiramente a pioneira no Brasil nos estudos da recepção e do uso do evolucionismo em várias esferas da vida nacional. Todavia, seu livro, Miranda Azevedo e o darwinismo no Brasil, não procura realizar uma análise minuciosa do discurso do personagem em questão, mas ao contrário, tenta inserir Azevedo em um ambiente intelectual, político e até epistemológico relativamente rico e bem mapeado. $\mathrm{O}$ que eu proponho é investigar a especificidade da narrativa de Azevedo para saber até que ponto é possível afirmar que ele tinha compreendido e usado de fato a teoria da evolução por seleção natural de Darwin. Incluindo-me em uma ortodoxia que vem desde Darwin, de maneira mais ou menos ininterrupta, assumo que a seleção natural é a única causa plausível para explicar e entender, em sua diversidade e adaptações, as funções de milhões de espécies de seres vivos, incluindo os vegetais, animais e humanos, além de inúmeras outras formas de vida. Eu queria apresentar mais diretamente como Miranda Azevedo se referiu a esses fenômenos e a suas explicações científicas. 
O progresso do homem brasileiro pelo meganismo de Seleção natural...

Metodologicamente falando, adoto a ideia de Mayr de que a teoria da evolução de Darwin pode, ou deve, ser compreendida, sob o risco de enorme confusão, como constituída por cinco outras teorias, a saber,

(1) evolução como fato - a ideia de que as espécies de seres vivos efetivamente se modificaram com o passar do tempo geológico; (2) origem comum - a ideia de que quaisquer dois indivíduos, de duas espécies quaisquer, e ao final e ao cabo, de todas as espécies, compartilham ancestrais comuns; (3) gradualismo - a ideia de que a mudança das espécies não é abrupta, do ponto de vista geológico, mas sim lenta e gradual; (4) especiação populacional - a ideia de que a evolução e a formação de novas espécies (especiação) são processos que ocorrem no nível das populações e não no dos indivíduos; (5) seleção natural - a ideia de que o mecanismo causal que promove a mudança evolutiva, ao longo das gerações, é o processo da seleção natural das variáveis favoráveis, que leva à evolução de adaptações, e em casos especiais à especiação (cf. Mayr, 1998, p. 564-5).

Mayr não afirma em momento algum que Darwin divide sua teoria assim, muito pelo contrário. Mayr sabe que o sistema de pensamento de Darwin, pelo menos na mente do naturalista inglês, era uma prodigiosa rede de argumentos, suportados por evidências, suportadas por argumentos e assim por diante. Assumo o poder analítico da proposta de Mayr para abalizar a leitura de Azevedo, mas estou atento à arbitrariedade dessa divisão.

\section{O darwinismo de Miranda Azevedo}

No dia 11 de abril de 1875 , diante de uma seleta audiência da qual participavam intelectuais, jornalistas, médicos, advogados, membros da aristocracia da corte, entre outros, incluindo o imperador, o jovem médico Augusto Cesar de Miranda Azevedo, com apenas 24 anos de idade, posicionou-se na tribuna e apresentou para a elite carioca o darwinismo, que ele acreditava ser fundamental para o desenvolvimento da nação. Meu objeto aqui é investigar justamente o texto da conferência, intitulada "Darwinismo: seu passado, seu presente e seu futuro". Ao meu ver, tal texto deve ser lido como um resumo das ideias de Haeckel contidas no livro História da criação natural que, por sua vez, é o resultado de uma série de palestras proferidas pelo próprio Haeckel em 1868 (Haeckel, 1961 [1868]). O próprio Miranda Azevedo explicita sua filiação quando diz que define o darwinismo com especial deferência ao naturalista alemão. 
O darwinismo, como diz Haeckel, não é mais do que um fragmento, uma parte dessa lei geral da interpretação dos fatos universais; defini-lo-ei, portanto, assim: a teoria genealógica que sustenta que todos os organismos extintos, existentes, futuros, e vegetais ou animais derivam-se de um pequeno número de tipos antepassados, excessivamente simples e transformados por uma evolução ou metamorfose gradativa por meio da seleção natural (Azevedo, 1876, p. 43).

Todas as espécies, incluindo a humana, descendem de ancestrais mais primitivos. A teoria genealógica de Darwin seria parte da teoria monista de Haeckel, uma lei mais geral que regulava todos os processos materiais na direção de uma transformação progressiva (cf. Haeckel, 1961 [1868]). Embora Darwin, em algumas passagens de sua vasta obra, faça uso de uma linguagem que admite uma escala de perfeição dos seres, vazada em termos como "superior" e "inferior", em nenhum momento ele parece pensar que seria possível escalonar todas as espécies em uma única linha ascendente de complexidade (ou mesmo linhas paralelas), ocupando o homem o ápice dessa escala. A única figura de $A$ origem das espécies é particularmente útil para visualizar que a espécie humana é apenas mais um dos inúmeros ramos vivos da árvore das espécies.

Como muitos leitores provavelmente sabem, foi a concepção de que homens e macacos compartilham um ancestral comum que mais imediatamente alvoroçou as mentes e os corações do mundo europeu (cf. Bowler, 1989; Mayr, 1998). Aideia de que o homem não é o cume da escala animal, mas que se origina de ramificações de espécies selvagens, teve mais impacto imediato do que a própria concepção mais geral da teoria da evolução, "as espécies se transformam com o passar do tempo geológico", e do mecanismo da transformação, a seleção natural. O "fato" de que o homem seria uma espécie que apareceu pela transformação de outras espécies, e de que a causa dessa transformação teria sido a seleção natural, ocasionou o que Freud afirmara ser uma das feridas narcísicas da espécie humana e do mundo ocidental.

Uma diferença gritante entre os textos de Miranda Azevedo e Ernst Haeckel é a sua extensão. Enquanto o do primeiro se estende por pouco mais de 20 páginas, o do segundo se avoluma a mais de quatrocentas, na edição portuguesa de 1961, com que trabalhei aqui. Dividido em 24, capítulos, Haeckel pôde se demorar em detalhar a história do evolucionismo e seu conflito com a filosofia dualista, a importância da doutrina darwinista, além de ter tempo para expor com detalhes sua própria concepção do evolucionismo, construindo várias árvores filogenéticas, não exatamente amparadas por dados empíricos, mas que oferecem a sua audiência uma revisão da história evolutiva dos grupos taxonômicos que teriam levado ao homem. Miranda Azevedo também segue uma estrutura desse tipo, mas muito mais reduzida. Ao considerar os primórdios 
O progresso do homem brasileiro pelo meganismo de Seleção natural...

do evolucionismo, situa o filósofo Leibniz em posição de destaque, em uma passagem em que fala de uma trama histórica que ascende até chegar à espécie humana.

Ganho incalculável de terreno foi para essa doutrina o nome do grande Leibniz, que, por prestígio seu, adiantou-lhe o triunfo em muitos anos. Com efeito, daí em diante numerosos sábios se ocupam com as investigações dos fósseis e aparecem trabalhos notáveis. Leibniz, por uma verdadeira inspiração filosófica, diz que "os homens ligam-se aos animais, estes às plantas e estas aos fósseis". Acreditando em uma lei de continuidade para todos os seres, considera-os como extensa cadeia cujos elos estavam tão estreitamente reunidos, que era impossível traçar os limites de um e outro (Azevedo, 1876, p. 45).

Essa "extensa cadeia" é a grande cadeia dos seres, a scala naturae que dominou a mente dos naturalistas, nos séculos XVII e xviıI, adentrou o século xıx, definhou no século xx (cf. Bowler, 1989; Mayr, 1998), mas vive ainda hoje na concepção de muitas pessoas que não tiveram oportunidade de alfabetizar-se cientificamente em biologia. Antes de qualquer ideia de um mundo de espécies em transformação, a compreensão ocidental do mundo das espécies entendia que o número de espécies era tanto quanto o que Deus tinha criado nos primeiros dias, como explicitado no Gênesis. Nas palavras traduzidas de Haeckel, citando Lineu, para se opor a ele: "há tantas espécies diversas quantas formas distintas criadas originariamente pelo ser infinito" (Haeckel, 1961 [1868], p. 32). Leibniz surge nesse cenário, para Azevedo, como aquele que conseguiu avançar o estudo sobre as espécies de seres vivos admitindo uma continuidade entre todas elas.

Em sua conferência, Miranda Azevedo também se refere a Charles Bonett, um dos principais naturalistas que pensavam como dar uma ordem à natureza das espécies em termos de cadeia ou escala.

Sobre estes fatos o naturalista Bonett criou sua célebre escala continua dos seres, na qual, com o auxílio das espécies intermediárias ou passagens, supôs um plano único de estrutura através de todas as gradações orgânicas por meio de uma só linha (Azevedo, 1876, p. 45).

Curiosamente, Leibniz e Bonett são os únicos dois autores que, salvo engano, não são referidos por Haeckel no livro A história da criação natural. Para Miranda Azevedo, o plano único incluía o homem no final da linha escalar. Evolution: the history of an idea, de Peter Bowler, apresenta uma versão da escala dos seres, proposta por Bonett, que reproduzo abaixo com pequenas adaptações: 


\section{A Grande Cadeia dos Seres}

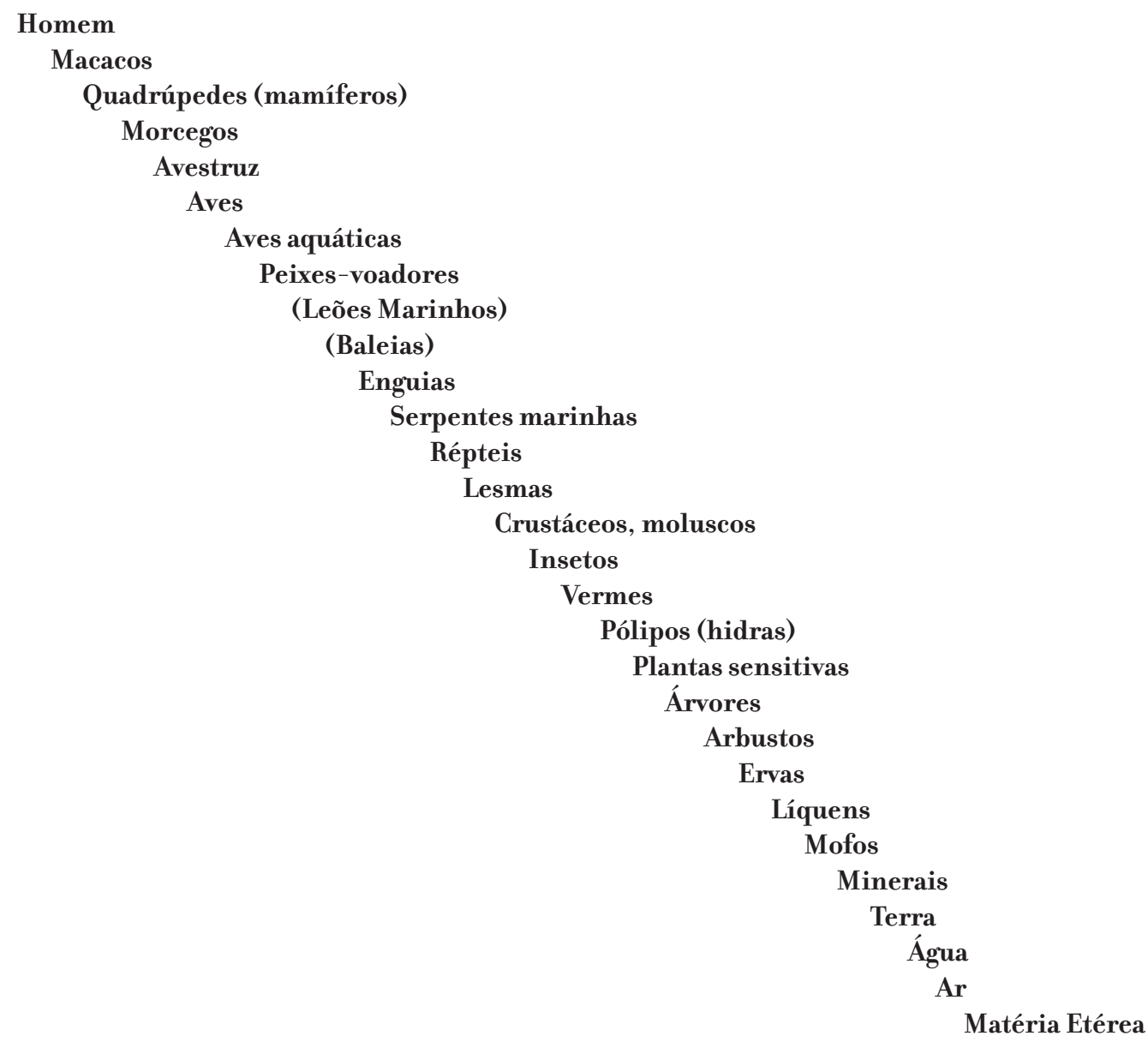

Figura 1. Diagrama que ilustra a grande cadeia dos seres. Adaptado de Bowler, 1989, p. 61.

No século de Bonett, considerava-se que cada uma dessas entidades (espécies, tipos) era fixa, não variava com o tempo. Na realidade, a escala não representa nenhuma história, nenhuma narrativa de desenvolvimento de um nível ou "degrau" para outro. As ervas não evoluem para arbustos, crustáceos não se transformam em lesmas, nem tampouco macacos em homens. Todas essas espécies foram criadas nos primeiros dias da criação, especial e independentemente. E, desde então, nenhuma espécie tinha se extinto e nenhuma espécie nova tinha sido criada. Ele havia dado a suas criaturas as estruturas necessárias para retirar seu sustento da natureza; a adaptação tinha sido um ato automático. E a espécie humana, aquilo que de mais perfeito Ele havia criado, tinha sido colocada sobre a Terra para ará-la e semeá-la, para domesticar seus animais, colher seus frutos e povoar com mais humanos os seus continentes. 
O progresso do homem brasileiro pelo meganismo de SeleçÃo natural...

Naturalmente, como Haeckel, Miranda Azevedo opõe-se a uma visão de mundo teleológica, dualista ou "mosaica”. Esse último conceito merece um minuto de consideração, porque enquanto ele vem grafado no texto de Miranda Azevedo como "mosaica”, em Haeckel, na tradução que utilizamos, a grafia é "moisaica”. No caso, ao que tudo indica, Haeckel e Azevedo queriam fazer referência à história bíblica de Moisés; portanto, eles identificam a escola moisaica com a tradição bíblica. A negação da teleologia, em Haeckel e Azevedo, diz respeito ao fato de que para eles as espécies não teriam sido o resultado de ação sobrenatural destinada a criar espécies dotadas de adaptações necessárias para suas respectivas funções de vida: nadadeiras para peixes, asas para aves, garras para predadores e assim por diante. Tais estruturas adaptativas seriam fruto de processos naturais.

\section{O progresso do homem para Miranda Azevedo}

Como no livro de Haeckel, a espécie humana é a espécie mais referida por Miranda Azevedo no texto da conferência. Haeckel reserva quase cem páginas exclusivamente para tratar da espécie humana, nas últimas três lições de seu livro. Na palestra de Azevedo, a palavra "homem", ou o seu plural, é usada nominalmente doze vezes. Obviamente o número de palavras não é um guia seguro, sobretudo se apresentado sem controle, sem saber, por exemplo, a frequência de outros animais não-humanos, de outros personagens ou mesmo de outros temas.

No entanto, o número de palavras e nomes pode ser um indício da importância dos referentes que tais palavras representam. Por exemplo, no texto de Azevedo, de vinte e duas páginas, o nome de Darwin aparece mais de trinta vezes, o de Cuvier, dezoito, os de Lamarck, Lyell e Saint Hillaire, nove, oito e sete, respectivamente. Em um texto que se refere a mais de cinquenta personagens históricos diferentes, dos quais apenas dezenove são referidos mais de uma vez, em um texto em que os conceitos de evolução e darwinismo misturam-se e confundem-se em mais de trinta referências explícitas, isso pode dar um panorama geral do que significam as referências de Azevedo à espécie humana. Das doze referências, duas não têm valor para nós, pois falam das "revelações preciosas de homens eminentes" e dos "homens da autoridade" (Azevedo, 1876 , p. 48), fazendo referência, no caso, a personagens históricos e não ao homem como produto da evolução.

Assim, seguindo mais uma vez Haeckel, quando Miranda Azevedo recapitula a história do evolucionismo, ele considera Lamarck o "verdadeiro fundador da teoria evolutiva". 
Lamarck traçou de uma maneira que surpreende as mais ousadas proposições, hoje encontradas na ciência. Estabelecendo a descendência e evolução progressivas dos organismos, do mais simples para o mais complexo, reconheceu que só eram reguladas pelas forças físico-químicas, da mesma maneira que os corpos inorgânicos. O homem, considerado de acordo com sua doutrina, ligava-se aos mamíferos superiores por intermédio dos quadrúmanos, e pela primeira vez, com coragem, sustentou a existência do homem-macaco.

É este, senhores, justamente um dos pontos, à primeira vista, mais delicados do darwinismo (Azevedo, 1876 , p. 4,6).

Azevedo considera que foi Lamarck quem avançou a ideia de que o homem também evoluiu de outras espécies, no caso um tipo de homem-macaco. Para compreender melhor esse ponto, é preciso determo-nos no tipo específico de transformação das espécies sugerido por Lamarck. A evolução para Lamarck é um processo histórico de modificações das espécies, que introduz a ideia de tempo na scala naturae. Afirmando que a complexidade e diversidade de espécies advinham, com o tempo, de outras espécies que um dia já foram mais simples, Lamarck sugere que as espécies não foram criadas independentemente, ao mesmo tempo (cf. Lamarck, 1984. [1809]; Bowler, 1989). Seu livro, Filosofia zoológica, é considerado o primeiro que trata da evolução. E, de fato, o livro não só explica o processo pelo qual tal transformação (Lamarck não usa a palavra evolução) ocorre, mas também localiza o homem e sua mente no ápice do processo. Lamarck pensava que a vida, em seus estados mais primitivos, era gerada espontaneamente da matéria inanimada, sob a forma de infusórios e outras criaturas ínfimas (cf. Lamarck, 1984. [1809]; Martins, 2007). Daí essas formas, ao se depararem com obstáculos no entorno ambiental, exercitar-se-iam para superá-los, o que, com o passar do tempo, derivava estruturas mais e mais complexas que levaram à espécie humana. Não há adaptação propriamente dita no texto de Lamarck (cf. Caponi, 2007). Lamarck compreende a anatomia e a fisiologia dos seres vivos como máquinas prenhes de fluidos (visíveis e invisíveis), que respondem com retrações e expansões aos obstáculos ambientais que a vida impõe.

Bowler representou graficamente a evolução de Lamarck. No eixo das abscissas encontra-se o tempo e, no das ordenadas, o grau de organização (ou complexidade). 


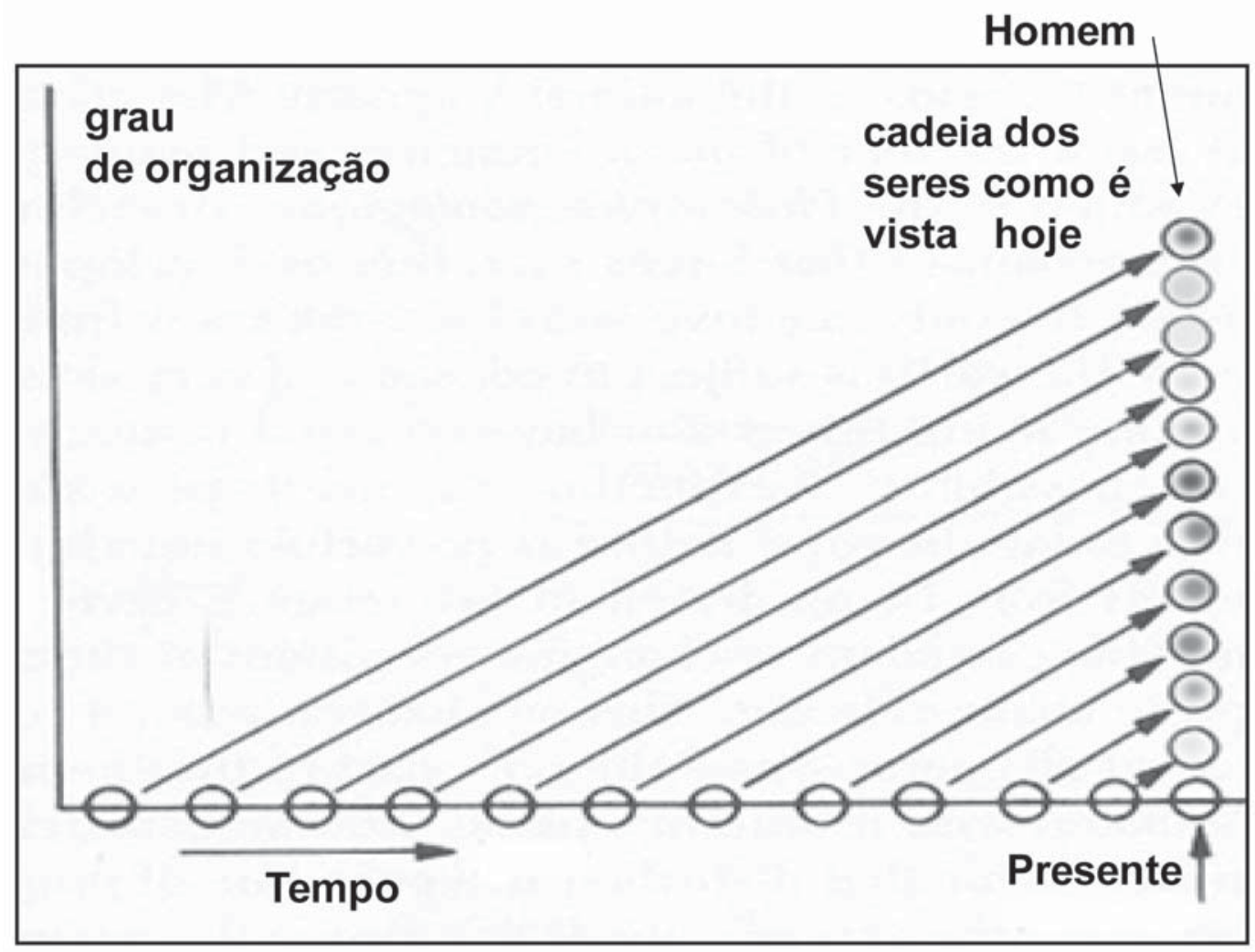

Figura 2. Diagrama que representa grafucamente a evolução de Lamarck. Adaptado de Bowler, 1989, p. 85.

Para Lamarck, quanto mais antiga é a origem de uma forma viva, mais perfeita é a espécie. Isso significa que a espécie humana, o círculo mais no alto do gráfico, é a espécie cuja origem por geração espontânea aconteceu há mais tempo. É claro que isso não significa que a espécie humana evoluiu diretamente dos infusórios, gerados espontaneamente. Mas sim, que a espécie humana é oriunda da mais antiga espécie que apareceu por geração espontânea, e que se transformou gradativamente em muitas outras espécies (que Lamarck chama de "massas") até chegar a nós. Somos parentes distantes desses infusórios, no esquema anterior, o primeiro círculo da esquerda inferior, mais próximo ao eixo das ordenadas (eixo vertical do grau de organização). Para Lamarck, temporalizando a escala dos seres, infusórios se transformam sim, com a passagem do tempo, em espécies mais complexas; girafas podem ter seu pescoço esticado, ervas podem evoluir para arbustos, crustáceos se modificam em lesmas e, eventualmente, macacos em homens. Como corolário das relações entre o tempo e o grau de organização, dá-se que quanto mais rudimentar for a forma viva, mais recente teria sido a origem espontânea de sua linhagem (como no caso do círculo da direita inferior, 
que teria evoluído há muito pouco tempo). Não fica claro, em Filosofia zoológica, se Lamarck pensa que todas as linhagens paralelas deveriam logicamente atingir o estado de perfeição humana, dado suficiente tempo para tanto.

Como se viu, Azevedo atribui a Lamarck não só a paternidade do pensamento evolutivo, mas também a ideia de que a espécie humana também era o produto transformado de outras espécies. As referências de Azevedo à participação da espécie humana no processo evolutivo estavam absolutamente sintonizadas com as discussões e debates que ocorriam do outro lado do Atlântico. Fazendo alusão à celebre audiência de 1860 , em que Huxley defendeu a teoria de Darwin das investidas do bispo Wilbeforce, ele reproduz as palavras do "buldogue de Darwin": "preferia mil vezes descender de um animal que se aperfeiçoava do que de um homem que ocupava sua inteligência em combater a investigação da verdade" (Azevedo, 1876, p. 47). Pretensamente, isso foi dito em resposta a uma provocação de Wilbeforce a Huxley, a respeito de sua ascendência, ou seja se ele, Huxley, descendia de um macaco pelo lado de seu avô ou de sua avó. O uso da palavra "homem" na resposta faz referência ao próprio Wilbeforce na figura do homem que estaria usando sua inteligência para impedir o estudo da verdade e ao mesmo tempo ao próprio Huxley, que preferia ser descendente de um animal nãohumano, do que ter relações de parentesco com inimigos da ciência.

Citando Goethe como um precursor do darwinismo, Azevedo assinala que o autor do Fausto foi responsável pela "grande descoberta do osso interno no homem, que o possui à semelhança de outros mamíferos". Essa semelhança anatômica seria mais tarde entendida como índice de parentesco, a despeito das intenções de Cuvier, fundador da anatomia comparada (cf. Haeckel, 1961 [1868], p. 38) e inimigo da ideia de evolução das espécies. Azevedo ressalta esse ponto dizendo que "nos trabalhos e nos esforços desse grande homem [Cuvier], contra as ideias de Lamarck e St. Hilaire, se encontram imensas provas em favor delas" (Azevedo, 1876, p. 4.8).

Na época de Lamarck, os fósseis humanos sequer haviam sido descobertos e identificados. Já Darwin e Haeckel, municiados pelos achados da nascente antropologia, impressionados pelos primeiros fósseis de neandertais, articulam as referências fragmentadas sobre uma história natural do homem, inferindo a continuidade entre nós e outras espécies, especialmente de mamíferos, particularmente de primatas. Desde $A$ origem das espécies, e atingind o o clímax em A origem do homem e a seleção sexual (Darwin, 2004 [1871]), Darwin é responsável pela articulação entre a ideia de origem comum e ideias gradualistas, populacionais e selecionistas. O conjunto dessas ideias aplicadas a uma tentativa científica de descobrir a história e os processos que levaram a espécie humana à condição que se observava ao tempo deles, desencadeou trabalhos científicos, de campo e de laboratório, que, por sua vez, sustentaram a teoria da evolução e abriram novos caminhos. 
O progresso do homem brasileiro pelo meganismo de SeleçÃo natural...

Haeckel cita Ernst Oken como um dos muitos naturalistas anteriores a Darwin que se pronunciaram contra a doutrina dualista ou teleológica de que o homem, como outros animais, tinha sido o resultado de um processo sobrenatural. As palavras de Miranda Azevedo, citando Oken, são as mesmas que as de Haeckel (cf. Haeckel, 1961 [1868], p. 72), mas em ordem invertida: “o homem não foi criado, mas desenvolveuse" (Azevedo, 1876, p. 51).

A história não tem contrafactuais. Não se pode saber como teria sido o desenvolvimento de um episódio histórico qualquer, se um outro episódio, causalmente relacionado a ele, tivesse sido diferente. É quase certo que a enorme celeuma que $A$ origem das espécies despertou não tivesse ocorrido, se Darwin não tivesse incluído a espécie humana no processo da evolução por seleção natural. Talvez demorasse mais um curto tempo até que alguém, complementando as ideias de Darwin, propusesse a origem animal do homem. Mas o que aconteceu de fato foi que, embora Darwin só se referisse ao homem muito marginalmente no livro de 1859 em três referências breves e significativas, seu estudo sobre a evolução do homem teve que esperar mais doze anos. Miranda Azevedo assinalou assim essa postergação:

as conclusões, aplicadas ao homem, foram calculadas e prudentemente deixadas para trás, e só em 1871 apareceram formuladas por Darwin na sua obra $A$ descendência do homem (Azevedo, 1876, p. 55).

Incidentalmente, é importante ressaltar que o título do livro de Darwin, Descent of man and selection and relation to sex, é muitas vezes traduzido para o português como A descendência do homem. É assim que Miranda Azevedo refere-se a esse livro. Duas considerações devem ser feitas. Primeiro, sobre a exclusão da seleção sexual do título e o desprezo justamente pelo mecanismo que Darwin propõe para explicar parte importante da diferenciação entre raças humanas e não-humanas. Segundo, sobre como seria mais correto traduzir a primeira parte do título: "A origem do homem" ou "A ascendência do homem", mas nunca como "descendência do homem". Pois, embora em inglês "descent" possa significar tanto "descendência" como "ascendência", em português esse significado duplo não se manifesta. Para usar a palavra "descendência" no sentido desejado por Darwin, o título teria que ser algo como "A descendência do homem a partir de um ancestral comum com outro primata (e a seleção sexual)”. De qualquer forma não faz sentido pensar que Darwin estava querendo falar da descendência do homem, mas de suas origens, seus ascendentes ou antecedentes. Miranda Azevedo escolhe uma tradução que se replica profusamente até hoje.

A teoria da evolução - cujo pai é Lamarck, e o triunfal tutor, Darwin, segundo Miranda Azevedo - é estruturada a partir de quatro leis naturais (Azevedo, 1876, p. 56- 
8): "luta pela existência" (p. 56), "variabilidade das espécies" (p. 57), "hereditariedade" (p. 58), "seleção natural” (p. 58). A questão fundamental é que o pretenso conhecimento das leis da hereditariedade e da seleção natural são o núcleo epistemológico do sistema de Haeckel, não o de Darwin. Embora Darwin reconhecesse a importância do processo hereditário, ele também tinha consciência de que não entendia direito como se dava o processo de transferência de características dos progenitores a sua prole, dos pais para os filhos. Já Haeckel assume que a herança de caracteres adquiridos (um tipo particular de herança tênue, herança afeita a assimilar ao patrimônio hereditário - genético - as características adquiridas durante a vida de um individuo) seria um processo absolutamente fundamental na criação das adaptações que serão selecionadas. Pelo uso e pelo desuso, funções e formas seriam desenvolvidas, e outras funções e formas seriam abandonadas.

Não é que Miranda Azevedo não entendesse o que Darwin propusera. Há de fato passagens extremamente lúcidas em relação ao processo genealógico proposto por Darwin, como quando Azevedo fala que a "marcha da inteligência de Darwin" foi profundamente marcada pela longa viagem no Beagle, principalmente em solo americano.

Na América, três grandes fenômenos impressionaram principalmente Darwin: a sucessão e substituição de espécies muito vizinhas, à medida que se vai do norte para o sul, o parentesco e semelhança das espécies que habitam o continente e as ilhas do litoral, bem como a variedade das [espécies] do arquipélago de Galápagos e, finalmente, os estreitos vínculos de relação existentes entre os mamíferos edentados e roedores contemporâneos com os fósseis das mesmas famílias. Nunca se esquecerá, diz ele, da surpresa que teve ao desenterrar os destroços do tatu gigante análogo ao tatu vivo (Azevedo, 1876 , p. 54).

Azevedo demonstra saber que os vínculos de parentesco são expressos pelas semelhanças existentes entre espécies geograficamente distantes, como as que habitam ilhas e continentes nem sempre muito próximos. Ou pelas semelhanças evidentes entre animais que não existem mais, como o tatu gigante, e os tatus que ainda existem. Onde Azevedo pretende parafrasear Darwin ao falar da analogia entre essas espécies, o leitor atual poderia ler como homologia, pois trata-se de semelhanças devido ao parentesco, e não à ação direta da seleção natural. No que diz respeito à seleção natural, Azevedo a compreendeu como o resultado da conhecidíssima luta malthusiana por recursos limitados.

É interessante saber que Darwin, meditando profundamente em suas opiniões, leu o livro admirável de Malthus e impressionou-se com a lei que estabelece esse 
O progresso do homem brasileiro pelo meganismo de SeleçÃo natural...

sábio do desenvolvimento das populações em progressão geométrica, e a proporção aritmética do desenvolvimento das substâncias próprias para a alimentação humana (Azevedo, 1876, p. $\left.5^{8}\right)$.

A luta pela sobrevivência é evidente na natureza e é ela quem faz as espécies progredirem, melhorarem:

É o vegetal que procura aniquilar o outro que lhe fica ao pé; para medrar um é necessário que definhe outro, este subtrai àquele uma quantidade de calórico, de luz, de umidade, de azoto ou carbono, por isso, este nutre-se enquanto aquele decompõe-se. Mais adiante é o animálculo devorado e presa do outro que precisa de seu elemento para viver; subi sempre em escala progressiva, do verme ao pássaro, deste à ave de rapina, generalizai e vede essa luta propagando-se entre todos os seres organizados até o homem, o rei da criação, que propaga e continua essa concorrência vital até seus semelhantes (Azevedo, 1876, p. 57).

Azevedo, sem dúvida, parece ser capaz de falar sobre as quatro leis que ele pensa serem constitutivas do darwinismo, incluindo a "lei da seleção natural". Vale lembrar que Miranda Azevedo não era naturalista, embora considerasse o estudo das ciências naturais fundamental para o desenvolvimento da nação (cf. Collichio, 1988; Cid, 2004). Esse é um mote que se repete pelo período; a ciência de ponta da época, tornando-se independente de suas raízes religiosas, é compreendida e usada como uma ferramenta essencial para alcançar a civilização, entendida aqui como o nível socioeconômico da Europa nas últimas três décadas do século xIx. Azevedo teria realizado pesquisas nos sambaquis brasileiros, inclusive obtendo achados arqueológicos, segundo Alfredo Löfgren, na Revista do Instituto Histórico e Geográfico de São Paulo, e Abilio Marques, na Revista Brasileira. Mas não há registros dessas pesquisas ou achados, além da menção nesses periódicos. Azevedo ainda teria escrito trabalhos sobre climatologia e antropologia, que nunca foram publicados ou localizados (cf. Collichio,1988, p. 33; Cid, 2004).

Acompanhando Haeckel, Azevedo considera a hereditariedade (reprodução) e a adaptação (nutrição) como duas faces do processo progressivo da evolução. A hereditariedade é conservadora, ela garante que as características vantajosas dos pais estejam presentes nos filhos. A adaptação é inovadora, pois permite que aquilo que foi adquirido durante a vida, se vantajoso, seja selecionado pelo uso e transferido para as gerações seguintes. O problema é que à época de Miranda Azevedo, Haeckel e Darwin, não se tinha uma ideia sequer coerente do mecanismo da herança. A ideia de que a mistura de sangue é que levava às características dos filhos era muito comum, mas ob- 
viamente não explicava por que os filhos, em muitas características, não se pareciam com os pais, mas com os avós, ou os tios, ou mesmo com parentes mais distantes. Miranda Azevedo diz que a hereditariedade é uma das quatro leis do darwinismo. Seguindo Haeckel, ele afirma que, no processo de adaptação ao mundo, os indivíduos obrigatoriamente nutrem-se de experiências as mais variadas, são modificados por elas, e essas modificações são passadas para a prole.

A lei da hereditariedade, a cada momento verificada pelo médico, nas heranças mórbidas, reconhecida e aceita pela crença popular que vê transmitirem os progenitores, as suas feições físicas, o seu caráter, e até as tendências aos seus descendentes, dá-nos a razão porque se transmitem essas variedades e tipos, que cada vez mais se acentuarão e se afastarão da origem primeva. Demais, o darwinismo estabeleceu o princípio que os indivíduos não produzem um ser igual ao seu, mas que produzem um organismo que lhe é análogo (Azevedo, 1876, p. 58).

Miranda Azevedo parece ter consciência de que é sobre essa variedade difundida até o nível do indivíduo que age a seleção natural: "entre os indivíduos da mesma espécie, oferece mais garantia de vitória e, portanto, de vida, os que têm melhores recursos de adaptação ao meio em que vivem" (Azevedo, 1876, p. 59). Mas quem tem os melhores recursos de adaptação? Os que vivem. E quem são aqueles que vivem? Os com melhores recursos de adaptação. Há uma circularidade entre sobrevivência e aptidão. Esse tipo de circularidade na definição da seleção natural pareceu minar historicamente a razão do próprio conceito. Mas essa é a apropriação que Miranda Azevedo teria feito de Darwin, um uso comum a outros autores, incluindo obviamente Haeckel. Mas a seleção natural não precisa ser, e talvez não deva ser, definida em termos de sobrevivência dos mais aptos ou fortes. Darwin percebeu a circularidade da definição, e escapou dela afirmando que sobrevivência e aptidão devem ser definidas em relação ao ambiente (cf. Gould, 1987). Hoje, pensa-se muito em seleção natural como reprodução diferencial, tendo-se em mente que as razões reprodutivas são bastante sensíveis a mudanças ambientais - ambiente entendido, sobretudo, com vieses biológicos, ou seja, constituído por muitas ou inúmeras espécies de seres vivos.

A questão é que, para Darwin, a perfeição parece apenas um momento de aparente equilíbrio entre uma espécie e o meio, um instantâneo da eterna mudança a que as espécies estão sujeitas no tempo geológico. Aideia de uma perfeição absoluta e (bem) acabada é completamente estranha a ele. No livro de 1871, A origem do homem e a seleção sexual, Darwin, depois de exibir homologias anatômicas entre os homens e os outros mamíferos, faz uma longa incursão pelo mundo de espécies onde machos e fêmeas apresentam diferenças sexuais secundárias, ou seja, diferenças entre os indivíduos de sexo 
oposto, diferenças essas não relacionadas diretamente aos órgãos sexuais. Essa enorme galeria, disposta ao longo de nove extensos capítulos (dos quais quatro são dedicados exclusivamente às aves), não parece estar disposta como uma linha única, mas em um processo arborescente de ramificações. Essa concepção de uma evolução ramificada, uma árvore com tronco, galhos e ramos que se bifurcam, foi representada por Darwin na única figura do livro de 1859.

Essa ideia de uma árvore está ausente em Miranda Azevedo. Haeckel construiu árvores genealógicas de protistas, de vegetais, de animais primários como "zoófitos" e "vermes" (Haeckel, 1961 [1868], p. 359 ss.), moluscos, radiados, vertebrados, mamíferos, incluindo as famílias e o gêneros dos macacos, abrangendo até o homem (cf. pranchas, p. 492-3). A partir dos dados disponíveis em sua época, e de sua fértil imaginação, Haeckel desenhou árvores que ele reconhece que atuam como hipóteses a serem confirmadas ou refutadas, sobretudo, a partir do registro fóssil. Aárvore de Darwin é uma estrutura geral que não se refere a nenhuma espécie determinada e que poderia e foi um modelo para pensar como as espécies se bifurcam. As árvores de Haeckel são fábulas destinadas a contar histórias de como surgiram determinadas espécies a partir de outras. Por exemplo, quando na página 493 ele apresenta uma de suas árvores genealógicas que incluem o homem, ele representa a evolução humana como o resultado genealógico dos antropóides asiáticos. Além do grupo humano, Pithecanthropi, na nomenclatura de Haeckel, na mesma época e do mesmo tronco teriam surgido o grupo dos macacos Hylobates (gibões) e Satyrus (orangotangos). Para Haeckel, o homem seria um produto asiático e não africano. Darwin acreditava o contrário (cf. Leakey, 1995) e as suspeitas do inglês estavam corretas. A questão é que as árvores de Haeckel, quando tratam dos grupos taxonômicos específicos, fabulam informações que nem de longe poderiam ser testadas à época dele. As árvores de Haeckel não se parecem muito com a árvore de Darwin, a despeito do fato de ambos usarem a mesma metáfora gráfica. Não porque a árvore de Darwin não especifique grupos taxonômicos. Mas por Darwin, de fato, estar mais preocupado com o processo geral genealógico de bifurcação que, para ele, implicava necessariamente a seleção natural. Já Haeckel sonha com oferecer o processo genealógico para grupos reais, vivos e extintos, sem preocupar-se estritamente com o mecanismo de separação das espécies; ou, melhor dizendo, Haeckel lança mão de um mecanismo que é muito devedor da ideia de que os processos naturais como que conduzem os organismos individuais, por meio do mecanismo da herança das características adquiridas, na direção de modificações que lhes permitam aproveitar os recursos do meio ambiente.

Azevedo não faz referência às árvores de Haeckel e Darwin. Assim como Haeckel, ele não explicita que a mudança evolutiva é uma transformação de populações e que, nesse tipo de processo, não faria sentido dizer que a espécie humana seria o ápice, pois 
cada final de ramificação representa uma espécie diferente. Mas acompanhando Haeckel, Azevedo não pensa assim.

Ainda outros raios brilhantes de luz são oferecidos ao darwinismo pela teratologia, a ciência das monstruosidades, e a embriologia que, demonstrando a identidade de origem e a metamorfose de todos os animais, nos mostra o mais perfeito da escala zoológica passando por todas as formas inferiores que a doutrina da evolução assinala para antecessores do homem. E o que é mais admirável é que esses fatos são [em] parte revelados por um dos mais sérios adversários do darwinismo, o Sr. Agassiz, que, contudo, arrastado pela verdade, deixa escapar a seguinte confissão: "é impossível distinguir e dizer se este crânio é de uma criança ou de um pequeno chimpanzé”!... (Azevedo, 1876, p. 59).

A espécie humana, superior a todas as outras, justamente por causa disso, ocupa um lugar privilegiado. Mesmo quando é anatomicamente impossível discriminar o crânio de uma criança e de um pequeno chimpanzé, é para chegar ao homem que a evolução parece passar por uma longa história de mudanças. Como para Lamarck, todas as outras espécies de seres vivos, todas as outras formas conhecidas ainda não atingiram a forma perfeita, a forma humana. E para chegar à forma mais perfeita, ao homem branco, europeu, do norte, é preciso tomar medidas políticas, decisões que afetarão diretamente as populações das gerações futuras. As implicações do darwinismo, para Miranda Azevedo, não são só naturalísticas e filosóficas. Elas não dizem respeito apenas à história das espécies, incluindo a humana, mas também podem e devem ter consequências práticas, pois é entendendo e obedecendo as leis naturais que seria possível melhorar a composição de uma população, como a brasileira, carente ainda das características progressivas e civilizadas do homem branco europeu. Assim, Azevedo como que coroa sua palestra com uma crítica a processos sociais que estavam ocorrendo no seu tempo, afirmando que o conhecimento do darwinismo certamente contribuiria para o progresso do Brasil.

Todo mundo grita que o gênero humano decai, que o homem de hoje não é o homem atlético e possante das eras passadas. Sabeis a razão disso? É pela aplicação da teoria de Darwin que a percebemos. Por todo mundo civilizado atualmente está grassando a preocupação do predomínio militar; e qual a causa dessa preocupação? A ignorância das leis de Darwin, na maneira por que são confeccionadas as legislações militares. Procuram para o exército os entes sadios, fortes, vigorosos e desprezam, deixam para constituir a família, para organizar a sociedade aqueles que têm alguns defeitos, que são fracos fisicamente. Qual a consequência 
O progresso do homem brasileiro pelo meganismo de Seleção natural...

desse fato? A consequência lógica e imediata de uma lei de Darwin da hereditariedade. Todos aqueles que forem robustos e sadios não podem constituir a família, porque as leis militares os roubam a seus lares para deixarem o sangue mais generoso e forte do país nos campos de batalha, e são precisamente os débeis, os que têm defeitos físicos que hão de constituir famílias, e assim transmitirem a seus filhos, a sua descendência os germens desse raquitismo, dessa degeneração que todos os estadistas proclamam (Azevedo, 1876, p. 60).

Miranda Azevedo profere a palestra enquanto o Brasil ainda vive o impacto da Guerra do Paraguai, que terminou em 1870. Um discurso que considere que seria mais inteligente deixar os melhores filhos em casa, como reprodutores das próximas gerações, não pode hoje receber outro nome diferente do que eugenia, embora nem a própria palavra houvesse, naquela quadra, sido inventada. Sob esse aspecto é surpreendente a semelhança entre os textos de Azevedo e Haeckel.

Sabe-se que para engrossar os exércitos permanentes se escolhem por conscrição rigorosa os mancebos sãos e robustos. Quanto mais vigoroso é um mancebo, melhor aparência, normalmente constituído, mais probabilidades tem de ser morto pelas espingardas de agulha, pelos canhões estriados e outros engenhos civilizadores da mesma espécie. Pelo contrário, os débeis, os doentes, com defeitos corporais, não servem para a seleção militar; ficam em suas casas em tempo de guerra, casam-se, reproduzem-se. Quanto mais estiolado, enfermo e fraco for um mancebo, tantas mais probabilidade tem de escapar ao recrutamento e de constituir família. Enquanto que a flor da juventude perde o seu sangue e a sua vida nos campos de batalha, o rebotalho desprezado, beneficiando de sua incapacidade, pode reproduzir-se e transmitir aos seus descendentes todas as suas fraquezas e todas as suas enfermidades. Mas pelas leis que regem a hereditariedade, resulta deste procedimento que as debilidades corporais e as intelectuais, que são inseparáveis, devem não só multiplicar-se, mas agravar-se (Haeckel, 1961 [1868], p. 126).

Quais são "as leis que regem a hereditariedade"? Como foi dito, nem Haeckel, nem Azevedo, nem Darwin conheciam as leis da hereditariedade, um problema que a ciência ocidental vinha debatendo fazia tempo. Haeckel, como Azevedo, acreditava que o mecanismo de herança incluía as características adquiridas durante a vida dos indivíduos. A posição de Darwin é mais ambígua; embora use sem dúvida a ideia de que as características herdadas durante a vida podem ser passadas a gerações seguintes, o mecanismo da seleção natural era muito mais importante. E a seleção natural obriga, 
em termos lógicos, que a herança genética não seja muito afeita justamente a modificações na ontogenia, ou seja, é necessário que haja a constância de uma herança robusta, mais ou menos imune a modificações reiteradas, para que o processo de seleção possa acumular as vantagens estatísticas conferidas por certas variações casuais que ocorrem em todas as populações, ao longo do tempo profundo. Dito de outra maneira, se a herança de características adquiridas fosse um mecanismo válido para explicar as leis da hereditariedade, a seleção natural, que assumi como núcleo identificador do darwinismo, seria destruído. Aqui reside o argumento mais sólido para filiar Azevedo a Haeckel, e não a Darwin. Embora Azevedo se refira à "leitura atenta que fiz" de $A$ origem das espécies de Darwin, em nenhum momento ele penetra no pensamento, proclamado pelo texto do naturalista inglês, de que a evolução é um processo que prescinde, e mesmo exclui, uma relação de causalidade direta entre variação individual e ambiente, de que o homem é apenas mais um dos ramos de um processo arborescente. De fato, Azevedo apresenta teses que fazem parte do darwinismo, mas faz isso seguindo Haeckel tão de perto que ouso anacronicamente considerar que a leitura atenta que ele fez foi a de textos do naturalista alemão e não do inglês.

Em Haeckel, a seleção natural apenas filtra a variação induzida pela alimentação, pelo ambiente, pela experiência, todos aqueles fatores determinantes que não são partes constitutivas do indivíduo, mas do seu meio. O sistema de Haeckel pode ser melhor compreendido sob a clave da famosa oposição nature versus nurture. Mas aqui a nutrição modifica a natureza via modificação no comportamento, nas funções e nos hábitos; o fenótipo, como o chamamos hoje, retrograda até o genótipo, os determinantes externos aos indivíduos modificam o que entendemos hoje por genótipo, e são esses indivíduos geneticamente modificados que irão ser positiva ou negativamente selecionados. Por isso, tanto para Haeckel como para Miranda Azevedo, pensar em uma reforma nas leis militares, abandonar a ideia de mandar para a guerra e para a morte os melhores jovens, é uma medida para imediatamente melhorar a população alemã e brasileira, via mecanismos hereditários e seletivos.

Embora a ideia na mudança dos critérios da seleção militar possa parecer uma forma adaptada de seleção natural no nível das populações, há de se considerar que as pessoas que passaram por esse tipo de seleção foram submetidas a testes físicos rigorosos, e que só há possibilidade de passar por essas provas para os sadios, para os bem alimentados e mais ou menos bem nascidos. Não basta apenas não mandar para a guerra os nossos mais fortes e melhores mancebos (e mandaríamos os mais debilitados, os mais fracos?); é necessário que os que fiquem para constituir uma família possam prosperar e progredir, tenham passado por uma nutrição (em sentido amplo) capaz de os dotar dos melhores traços de um reprodutor que vai contribuir com o futuro do país, e incluí-lo no concerto das nações. As leis de Darwin que Azevedo seguiu são as de 
Haeckel, que mais tarde serão as da eugenia europeia e americana e depois do nazismo de Hitler.

O homem, representado por Miranda Azevedo, é uma espécie resultante da progressão do processo genealógico da evolução. Haeckel diminui a importância da seleção natural admitindo a herança tênue das características adquiridas. Azevedo, obviamente, não percebeu essa contradição. Entretanto, se o compromisso de Darwin com a seleção natural é o que de fato singulariza sua teoria da evolução e o darwinismo, Haeckel e Azevedo se afastam dele. A espécie humana para Darwin, com todas as suas variações de raça, é o resultado de processos seletivos, às vezes, mas não sistematicamente, alimentados pelo uso e pelo desuso. A seleção natural e a seleção sexual nutrem-se principalmente de variações que não são causadas pelo hábito e pela necessidade, mas são o resultado de processos casuais, semiestocásticos: variação aleatória selecionada por critérios específicos para cada ambiente histórico.

"Atores ecológicos em um cenário genealógico" é o título de um artigo do filósofo David Hull, sobre a definição de espécie biológica. Claro que Azevedo não atenta para essa relação entre agentes que lutam ao longo de inúmeras gerações para deixarem seus representantes para as gerações futuras. Como Darwin, Azevedo não sabe da existência de genes. A diferença é que enquanto Haeckel e Azevedo pretendem ter pleno conhecimento das leis da herança, Darwin reconhece sua ignorância. E adota o caminho de que as variações entre os indivíduos não são o resultado da necessidade ou do esforço desses organismos. Ao longo do tempo genealógico, as pequenas diferenças entre os indivíduos podem ser selecionadas em uma mesma direção e darem origem às estruturas adaptativas e a novas espécies. Para ter uma reflexão evolutiva dessa natureza, o Brasil teve que esperar muito mais tempo, provavelmente apenas em meados do século xx, em 1943, com a chegada de Dobzhansky ao Brasil.

\section{Conclusão}

Na minha opinião, a conclusão é inadmissível. Borges, O Aleph, p. 21.

O ano de 1875 é de particular importância para a recepção e uso do darwinismo no Brasil porque, além da conferência de Miranda Azevedo, dois outros personagens estiveram envolvidos com a divulgação da teoria da evolução: Emílio Zaluar publicou o romance intitulado Doutor Benignus, no qual pretende aderir abertamente à teoria da evolução, além de propor hipóteses sobre a origem do homem brasileiro; Domingo Guedes Cabral tentou em vão defender sua tese de doutorado As funções do cérebro, na 
qual propunha uma concepção do cérebro humano que se baseava largamente em processos evolutivos e materialistas. A tese foi rejeitada pela Faculdade de Medicina da Bahia, mas o texto saiu publicado um ano mais tarde, em 1876, financiado pelos colegas de turma de Cabral, que escreveu às pressas uma tese sobre febre amarela para poder obter seu título de doutor. De fato, Azevedo pode ser considerado o pioneiro sobre a recepção e uso do darwinismo no Brasil, pois, em sua tese de doutorado de 1874, em uma das seções acessórias, ele já se apresentava como adepto da teoria da evolução.

É difícil dizer se a palestra proferida por Miranda Azevedo exerceu algum impacto sobre os outros dois autores, instigando-os a usar ideias evolucionistas em seus próprios textos. Essa primeira palestra de Miranda Azevedo, assim como as outras não transcritas e publicadas, foram comentadas positivamente em jornais da época, como Jornal do Commercio e O Globo (mesmo jornal em que sairia publicado, em fascículos, o Doutor Benignus) e, negativamente, em O Apóstolo. É bastante plausível pensar que essa repercussão tenha incitado ou estimulado Zaluar e Cabral a expor suas próprias ideias. Embora Cabral vivesse em Salvador, Zaluar residia no Rio de Janeiro, e não é difícil imaginar que este último inclusive estivesse presente em uma das palestras de Azevedo, na Freguesia da Glória.

Que impactos esses textos, essas vozes, tiveram no futuro do uso e recepção do darwinismo no Brasil é um assunto até agora nada estudado. Os três textos em questão apresentam concepções de evolução e da espécie humana, que buscam encontrar soluções para a supostamente débil conformação do povo brasileiro. No caso de Miranda Azevedo, trata-se de criticar a seleção militar porque ela tira da população seu melhor sangue. No caso de Zaluar, é a ideia de que o homem branco iria servir de tutor para as raças indígenas que habitam o interior do Brasil, ainda imperial, no caminho do progresso e da civilização. No caso de Cabral, é a possibilidade de regenerar o cérebro de loucos e criminosos (majoritariamente não brancos) para que retomassem a marcha do cérebro progressivo alimentado pelo combustível, pelo óleo da educação e do ensino.

É importante ressaltar que a tese de ${ }_{1874}$ de Miranda Azevedo tratava de um assunto de importância de saúde pública, o beribéri. Em outra de suas seções acessórias, Azevedo foi obrigado a responder uma questão sobre higiene. Ele argumenta em proposições que englobam propostas tanto para a higiene física quanto moral. Depois que trocou o Rio de Janeiro por São Paulo, Miranda Azevedo lecionou higiene e saneamento. Também tornou-se deputado pelo estado de São Paulo, fazendo propostas de saneamento, como aquela para a Várzea do Campo (cf. Cid, 2004). Higiene e saneamento iriam tornar-se temas mais e mais candentes nas décadas posteriores, atingindo seu clímax nos movimentos intelectuais e políticos entre o final da década de 1910 e a eclosão da Primeira Grande Guerra, entre eles, movimentos eugênicos (cf. Stepan, 
2005; Lima \& Hockman, 1996). Até que ponto Miranda Azevedo e os outros dois autores são precursores de um movimento eugênico no Brasil, ou fazem parte de um processo muito antigo de pensar melhoramentos nas populações nativas, é uma questão que demanda mais investigações. De qualquer forma, a teoria da evolução parece ser a chave usada por ele para conceber que as populações humanas não são fixas e que fatores ambientais são a causa da debilidade geral da gente que nascia e vivia no Brasil. Todavia, esse não era exatamente um problema de nascimento ou, como se diria hoje, genético: tratava-se, ao contrário, do estado selvagem e depauperado do entorno físico e moral das regiões não tocadas profundamente pela civilização.

Note-se que, em 1875, o conceito e a própria palavra "eugenia" ainda não existiam, embora movimentos eugênicos tenham ocorrido ao longo de toda a história (cf. Popper, 1974). Miranda Azevedo vislumbra no darwinismo um instrumento para aperfeiçoamento do homem brasileiro. Embora sua combinação entre mecanismos de hereditariedade e seleção esteja claramente radicada nas ideias de Haeckel, e não nas de Darwin, isso não significa que Azevedo não deu voz, no Brasil, ao pensamento do autor de $A$ origem das espécies. A coragem e a habilidade para articular no mesmo texto as ideias de evolução em geral, de evolução humana e de seleção natural, quando o poder, sobretudo da Igreja, apenas começava a ser questionado, chega até os dias de hoje como que clamando para que se investigue mais como a mente de brasileiros do final do século XIX concebeu a teoria da evolução, quando defendia seus próprios interesses políticos e epistemológicos. $\$$

\author{
Ricardo WAIzBoRT \\ Pesquisador titular do Instituto Oswaldo Cruz, \\ Professor dos Programas de Pós-Graduação \\ em Ensino de Biociências e Saúde \\ e em História das Ciências e Saúde, \\ Fundação Oswaldo Cruz, Rio de Janeiro, Brasil. \\ ricardowaizbort@yahoo.com.br
}




\section{ABSTRACT}

The aim of this work is to discuss "Darwinism: its past, its present, its future", a lecture given in 1875 by Miranda Azevedo as one of the "Popular Lectures of the Gloria Neighborhood, Rio de Janeiro". In this lecture Azevedo elaborates the concepts of evolution, human evolution, progress and the idea of man as the pinnacle of evolution and the master of the selective laws governing nature. We will analyze the article, published in 1876, that contains the full text of Azevedo's lecture. Of particular importance is his affiliation to Haeckel, something already commented on in Brazilian historiography. But, unlike other studies devoted to the theme, I will examine in detail Azevedo's text, attempting to show how he relates hereditary and selective evolutionary processes to thinking about how future Brazilian generations could progress.

KeYwords • Brazil. Darwinism. Evolution. Natural selection. Progress. Heredity.

\section{REFERÊNGIAS BIBLIOGRÁFIGAS}

Alonso, A. M. Ideias em movimento: a geração de zo na crise do Brasil Império. São Paulo: Paz e Terra, 2002. Azevedo. A. C. M. Beribéri. Rio de Janeiro, 1875 . Tese (Doutorado em Medicina). Faculdade de Medicina do Rio de Janeiro.

. Darwinismo: seu passado, seu presente, seu futuro. Conferências Populares da Freguesia da Glória. Rio de Janeiro: Typographia e Impr. Const. de J. Villeneuve S. G., 1, a10, 1876. p. 41-63.

Bowler, P. Scientific attitudes do darwinism in Britain and America. In: КонN, D. (Ed.). The darwinian heritage. Princeton: Princeton University Press, 1982. p 641-81.

. Evolution: the history of an idea. Berkeley: University of California Press, 1989.

CAPoni, G. Contra la lectura adaptacionista de Lamark. In: Rosas, A. (Ed.). Filosofía, darwinismo yevolución. Bogotá: Universidad Nacional de Colombia, 2007. p. 3-17.

Cid, C. M. R. O aperfeiçoamento do homem por meio da seleção: Miranda Azevedo e a divulgação do darwinismo, no Brasil, na Década de 1870. Rio de Janeiro, 2004. Dissertação (Mestrado). Casa de Oswaldo Cruz.

Collichio, C. T. A. F. Miranda Azevedo e o darwinismo no Brasil. Belo Horizonte/São Paulo: Itatiaia/Edusp, 1988.

Darwin, G. R. A origem das espécies. Tradução E. Amado. São Paulo: Itatiaia, 1985 [1859]. A origem do homem e a seleção sexual. Tradução E. Amado. Belo Horizonte: Itatiaia, 2004, [1871].

Dennett, D. G. A perigosa ideia de Darwin. Tradução T. M. Rodrigues. Rio de Janeiro: Rocco, 1998.

Domingues, H. M. B. et al. (Ed.). A recepção do darwinismo no Brasil. Rio de Janeiro: Editora Fiocruz, 2003.

Domingues, H. M. B. \& SÁ, M. R. Controvérias evolucionistas no Brasil do século xix. In: Domingues, H. M. B. (Ed.). A recepção do darwinismo no Brasil. Rio de Janeiro: Editora Fiocruz, 2003. P. 97-123.

Fonseca, M. R. F. As "Conferências Populares da Glória”: a divulgação do saber científico. História da Ciência da Saúde-Manguinhos, 2, 3, p. 135-66, 1996.

Gould, S. J. Darwin e os grandes enigmas da vida. Tradução M. E. Martinez. São Paulo: Martins Fontes, 1987 .

GLIcK, T. F. (Ed.). The comparative reception of darwinism. Chicago: The University of Chicago Press, 1988.

Glick, T. F. et al. Introducción. In:___. El darwinismo em España e Iberoamérica. Ciudad de México: Universidad Nacional Autónoma de México, 1999. p. 14.

Gualtieri, R. G. E. Evolucionismo no Brasil: ciência e educação nos museus (1870-1915). São Paulo: Editora Livraria da Física, 2008. 
O progresso do homem brasileiro pelo meganismo de SeleçÃo natural...

Haeckel, E. História da criação natural ou doutrina científica da evolução. Tradução E. Pimenta. Porto: Lelo \& Irmão Editores, 1961 [1868].

Конм, D. (Ed.). The darwinian heritage. Princeton: Princeton University Press, 1982.

Huld, D. Darwinism as a historical entity: a historiographic proposal. In: КонN, D. (Ed.). The darwinian heritage. Princeton: Princeton University Press, 1982. p. $77^{3-811 .}$

Lamarck, J. B. Zoological philosophy. Chicago: The University of Chicago Press, 1984, [1809].

Leakey, R. A origem da espécie humana. Tradução A. Tort. Rio de Janeiro: Rocco, 1995.

Lima, N. T. \& Hochman, G. Condenado pela raça, absolvido pela medicina: o Brasil descoberto pelo movimento sanitarista da Primeira República. In: Maio, M. C. \& Santos, R. V. (Ed.). Raça, ciência e sociedade. Rio de Janeiro: Editora Fiocruz, 1996. p. 23-4,0.

MaIo, M. G. \& Santos, R. V. (Ed.). Raça, ciência e sociedade. Rio de Janeiro: Editora Fiocruz, 1996.

Martins, L. A. P.A teoria da progressão dos animais de Lamarck. Rio de Janeiro: Booklink/FAPESP/GHTC, 2007 .

Mayr, E. O desenvolvimento do pensamento biológico. Tradução I. Martinazzo. Brasília: Editora da UnB, 1998.

Popper, K. R.A sociedade aberta e seus inimigos. Tradução M. Amado. São Paulo: Edusp, 1974.

Rosas, A. Filosofía, darwinismo y evolución. Bogotá: Universidad Nacional de Colombia, 2007.

SÁ, D. M. A ciência como profissão: médicos, bacharéis e cientistas no Brasil (1895-1935). Rio de Janeiro: Editora Fiocruz, 2006.

Stepan, N. L. A hora da eugenia: raça, gênero e nação na América Latina. Rio de Janeiro: Editora Fiocruz, 2005 . 